\title{
Civilization and City Images in the Films of Georges Méliès
}

\author{
Ekaterina Salnikova ${ }^{1, *}$
}

${ }^{1}$ The Media Art Department, the State Institute for Art Studies, Moscow, Russia

${ }^{*}$ Corresponding author. Email: k-saln@mail.ru

\begin{abstract}
The very first images of civilization and city in Georges Méliès fiction films are described in the article. His vision of "islands" of a civilization in the middle of a stony landscape and active aircraft traffic were adopted by science-fiction cinema later. In his travel films, the director creates the image of civilization not so much with the help of the spatial environment, but with references to the world of science, entertainment and spectacular urban culture. Méliès became the author of the first images of city roofs, the Middle Age city screen myth, and the confrontation of traditional city and modern technical civilization.
\end{abstract}

Keywords: silent cinema, Georges Méliès, An Adventurous Automobile Trip, the Legend of Rip van Winkle,

Christmas Dream, city, civilization, distraction, locations

\section{INTRODUCTION}

Studies on city images in art are an important component of a modern interdisciplinary science. At the State Institute for Art Studies, this issue was developed as part of the study on popular culture and mass media, which was reflected in such collective works as "Entertainment and a City" [1]. The Research Institute of Theory and History of Fine Arts of the Russian Academy of Arts holds regular conferences on the interpretation of a city mainly in traditional arts. One of the most outstanding publications was a collective monograph called "Cities of the world - the world of the city" [2]. The author of this article has recently written about city images in modern cinema in the monograph "Visual culture in the media space..." [3] This topic is also of interest to modern foreign researchers [4]. Cinema appears to be an increasingly frequent subject of consideration, since in this type of art, which appeared already in the era of urban culture, the theme of a city sounds particularly intense and artistically expressive. A city proves to be necessary as a place bustling with activity and a three-dimensional decoration for contemplation, as a living environment with a recognizable atmosphere and at the same time as a kind of myth that emerged in pre-screen arts.

Reflecting on the aesthetic interpretation of a city, Barbara Mennel writes about the connection of a city with the images of a station and a train, which are correlated with the phenomenon of cinema, since both trains and cinema manipulate time, absorb space and contribute to the emergence of a concept of universal time [5].
In this case, however, an image of a city is even more directly related to cinema, since it exists on the screen in most cases as an abstract city space or even "an illusion of a city". As a rule, it is created from a number of fragments of an urban environment, whether it be nature or scenery. In fact, shooting a city as such in a real urban environment is a very complex organizational and technical task. Therefore, it is an "abstract space" of a city with a view of its interiors that is assembled and, most importantly, combined with our city associations in spectators' minds. Thanks to this, an illusory integrity of a city image lives an organic screen life.

There are two approaches in the modern science. The first one is the inclusion of the reflections on cinema images of the city in silent films into cultural studies on the phenomenon of a city. The second approach is the study of urban landscapes in masterpieces of German cinema of the 1920s [6]. Take for example "The Cabinet of Dr. Caligari" by Robert Wien or the city in Fritz Lang's "Metropolis". What is left behind is the question of where the history of city images in feature films began.

This article discusses the very first images of a city in the movies of Georges Méliès, a pioneer of art and fiction films. The thing is that the views of a city appear later than view of civilized space in his works. Therefore, we are going to focus on the latter, as they are direct predecessors of city images in art cinema. 


\section{Civilization IMAGeS}

It is in Méliès's movies that we can first see the emergence of a city illusion in feature films. That was the time when the tradition to create a city illusion putting together separate, fragmentary locations was not formed yet.

In "A Trip to the Moon" ("Le Voyage dans la Lune", 1902) and "An Impossible Voyage" ("Le voyage à travers l'impossible", 1904) separate locations, such as the lecture hall, the station, the hospital and the restaurant in the hotel are connected with each other not by spectators' imagination, by default completing the entire urban landscape, but by the picture of a rocky and uneven desert terrain with a fantastical vehicle moving by. As a result, there is not an image of a city or moving from one city to another, but a picture of an "alternative civilization". It has separate spots of intellectual activity, domestic comfort, and technical work. However, they are located in the midst of a vast wasteland, where it is easy to get lost or find oneself in a dangerous situation.

This wasteland, as a "bridge" between different locations, unwittingly creates a picture of the Earth, the way Adam and Eve, who had just been expelled from the gardens of Eden, could have seen and perceived it. Undeveloped, uncomfortable, requiring a lot of time and effort to transform wildlife into a civilized space. The future, symbolically embodied in the images of technological marvels, forms a "collage" with a picture of an almost mythological past. Characters traveling in the past using transport of the future - this is the present. Later on, the motif of a desert area with rare human settlements and fantastical transport will be repeatedly used in fiction films, up to "Mad Max...".

Méliès clearly values the view of "the planet in general" or "the universe in general" above the views of real Paris or any other city. Like emptiness and black screens [7], which were used usually by the director, a desert is easier to work with. Therefore, in early fiction films, the animated and even partly "urbanized" expanse of the sky and space looks more expressive. In "The Conquest of the Pole" ("À la conquête du Pôle", 1912) intensive traffic occurs in the sky with the most bizarre aeronautic vehicles flying around. In many movies of Méliès, space creatures appear, such as a shooting star, a maiden comet, or a man-planet. The moon is usually feminine, while Saturn and Mars are pointedly masculine. Being in his house or attached to his space body, the man-planet hovers, floats and enjoys boundless open spaces of the universe.

While in all the three "journeys" mentioned above an urban landscape has not yet developed as a screen illusion, "An Adventurous Automobile Trip" ("Le raid Paris-Monte Carlo en deux heures", 1905) comes very close to that. The first scene shows a media event - the start of an auto trip. Its participants get into their cars in front of an interested crowd. In the background, you can see a facade of a public building in antique style according the "Catalogue..." it is the Paris Opera, Opera de Paris [8]. Then a car starts, goes, makes stops - sometimes planned, like at a gas station, sometimes involuntary. But everywhere it goes it causes accidents, destruction and chaos. They drive it into buildings and people overturn counters. One of those who was run over at a gas station turns into a completely flat body. In order to revive him, other characters have to take up the pumps and inflate the poor guy who eventually starts to shudder and show signs of life (a dummy body is used). Finally, after the compassionate citizens all push hard enough and crowd the victim around, he is fully restored as a living person (the dummy is replaced by a live performer).

This way Méliès gives a feature film the idea of euphoric destruction of civilized space and shows the principle of enjoyment which lies in the abolition of the everyday fear of destruction, in lifting the ban on spoiling things that governs civilized humanity. An urban environment is subject to destruction in the first place, since it is more man-made, more interesting to break without considering yourself a destroyer of natural harmony and apparently without feeling any remorse.

Since the time Méliès had fun with the habitat being destroyed, there has been nothing innovative in this motif in cinema. The nuances have been improved, the production costs have increased (especially in projects like "007"), witty behavioral models have been invented (for example, in Hitchcock's films). However, the very essence of the concept of enjoyment (including the enjoyment of horror) at the sight of civilized chaos on the screen remains unchanged.

Improvements in a civilized living environment are not automatically regarded as positive by Méliès. Everything is much more complicated. In the film called "The Legend of Rip Van Winkle" ("La legend de Rip Van Winkle"; "Rip's Dream", 1905), the issue of changes in the character's living space is very revealing. In the original fiction story by Washington Irving, Rip van Winkle falls asleep for as many as 20 years. When he wakes up and returns home, no one seems to recognize him. He runs off into the woods from his pursuers, falls asleep and has a dream about how he slept for 20 years and returned to his native place.

So how does the character picture the future of his native village in his dream? It has become more civilized, well-groomed, equipped with beautiful objects! Instead of a shaky bridge, barely fenced with pitiful twigs, there is a stone bridge with a series of columns and with a beautiful stone or even a marble staircase descending onto solid ground. Instead of coarse rustic chairs and a table near the house, there are 
a few tables with elegantly shaped chairs. The sign on the house door says that it is now a hotel. Instead of an ordinary well, there is a well with a fancy tall decoration, which almost obstructs the view of the ancient church in the background. Behind the bridge now, there stands a rather massive house, while before there was a small one. One can feel the care of architects and even the semblance of design, which in general makes the living environment somewhat deliberately decorative, as if intended for admiration. It is in such "genuinely" rural corners that you can expect an influx of tourists looking for aesthetic experiences. The clothes of the inhabitants of Rip's native area have also become more elegant. The village has turned into the place "for show" and probably for successful business.

It should be noted that the concept of change, created by Méliès, looks like anticipation of a "primeval" beauty, cultivated by tourist business these days. Although we do not see an urban environment in this movie, at the sight of the village "twenty years later", there is a feeling of complete urban domination. In fact, it is an urban world that looks at a rural life from the outside and makes idle visits to rural settlements, which requires a toy village, a village-forthe-weekend, a village as a "leisure zone".

All the improvements in the rural environment, being also losses, according to the film, were too high a price to pay. The village has become new, but ostentatious, and the character has grown old, which he sees in horror, scooping up water from the updated well. Now he is a stranger here. Women repel Rip, and the guy whom Rip wants to ask about what happened is terrified of a stranger. Now the locals are gathering, armed with pitchforks and a broom to protect themselves from this decrepit stranger. The villagers are obviously hostile to the stranger. Civilization has come as an external, material update, but not as tolerance, openness, interest in the unfamiliar.

Fortunately, all this is just a dream. Having woken up, Rip returns to his native village with a shaky bridge, a simple well and an unobstructed view on a few houses and a church in the distance. Méliès complicates the original plot, turning the fiction reality of the novel into a nightmare. However, it does raise suspense. The main theme in the film is not the lost time of life, but the horror of the very danger of it and the difference between the world of the present and the world of the future. Méliès is afraid of external changes in the living environment, and he is even more concerned about a simple ingenuous person who might not belong in the improved space of everyday life.

\section{MOVEMENT AROUND ONE BUILDING}

The first thing that appears in Méliès's films as a city landscape is a corner building or a building with an arch, through which one can see a street going deep into the frame. A comedy film "Colonel's Shower" ("La douche du colonel", 1902) shows repair works being carried out by the military on the scaffold in such an arch. An officer is going to quietly sit under the scaffold enjoying the sense of his personal dignity and the advantages of his high rank (he should not work; he only observes and gives orders). In the end, however, either paint or water from a bucket gets spilled on him, so he loses both his rest and a sense of superiority. All this happens with a cute city street, which can be seen through the arch, in the background.

In other words, as soon as a hint of urban space emerges, it comes with the motif of the adversities of life. In urban space, at any moment something unforeseen might happen that would suddenly make the life of all or some of the characters go off the rails.

In "Unexpected Fireworks" ("Un feu d'artifice improvise", 1905), the action takes place in front of a fireworks shop. First, we can see a quarrel between a woman and an old man, who is apparently begging her for money. Perhaps this is her husband in need for a drink. He tries to embrace the woman, but she pushes him away, and the old man falls down and lifts his legs, which looks like nothing but a theatrical performance or a circus sideshow. The woman leaves, having reluctantly given the old man a coin. The latter stands up, embraces a lamppost, relieves himself in the corner, at the wall of the shop and finally falls asleep on the ground by a lamppost.

Shortly afterwards, six young people come, one after another. Their appearance is very theatrical and looks like a part of a comic dance. Bending over the sleeping old man, the whole company discusses him and decides to play a trick on him. The young people break into the store, take out fireworks, attach them to the post and set them near the old man on the ground. After that, all the rakish young men scatter around. Some of them take shelter in the shop, others climb over the nearest fence. The remaining one stays there and sets fire to the fireworks. They go off. The old man shudders, jumps up, falls down, jerks his legs in the air, jumps up and falls down again, tumbles, etc. The young people get back off the roof and have fun, jumping and dancing in the smoke. At their parting, the whole company runs up to the camera and, continuing to play the fool, looks and laughs into it before running away.

This direct look into the camera and the behavior of the young people, who seem to be very well aware of what kind of equipment it is, is the best evidence of how "advanced" modern pranksters are. It ends exactly like a city event in the frame, perhaps a rally in front of a pre-set camera, but not like a farcical theatrical scene, the way it all started. Paradoxically, here the technique of detecting the camera and filming gives the events the 
atmosphere of a modern city, which is associated with the latest technology of that time.

A number of tricks take place in a comedy "Misfortune never comes alone" ("Un malheur n'arrive jamais seul", 1903). A guard at the entrance door with the "Corps de Garde" sign falls asleep. Meanwhile, life goes on. A lamplighter comes to repair a lamp. Then a prankster appears, takes the gun from the guard and puts a hose in his hand instead. When a strict officer walks past and comments on the sleeping man, he shudders, which puts the hose into action. Water gushes to the officer's face and over the lamplighter. The latter drops the lamp post directly onto the officer, and his head takes place of the light bulb. It is followed by fussing around in front of the house and running / jumping inside.

The corner house here is similar to an illusionist's magic box, which has grown to the size of a building. However, its essence is the same - this thing seems static, unchanging and predictable only for a short while. In fact, the house turns out to be full of entrances and exits in the form of windows and doors, so anyone can jump or fall out from anywhere. Anyone can also jump, break or sneak in. Chases and confrontations through appearances-disappearances in this amazing house look like an endless theatrical or circus performance with a lot of acrobatics elements. But this is not enough. The characters bring a booth and leave it in front of the house. After that, the booth also starts functioning as a magic box.

Nevertheless, with all the theatre and, therefore, convention of this "city spot", there is something that supports the city illusion. These are characters that appear from the left and right, from inside and outside of the house and leave the frame going in different directions. Such a free movement creates the effect of an open environment letting in and out an unlimited number of new people. A frame becomes a part of a flow-through system with a kind of "filter" that makes the "flows" of actors stop and engage in close physical interaction with the house and the booth.

In modern cinema, there still works the principle of one location for the entire film, with fixed multidirectional movement around this location or with a fragment adjacent to it and located frontally or diagonally to the audience. In "The Place" (2017, director Paolo Genovese), for example, all the action takes place in a cafe, in the dialogues that the protagonist of the film, similar to the good devil, conducts with his clients, whose affairs he means to settle. From time to time, we can see only a little spot in front of the glass wall of the cafe. This transparent wall, a neon sign above it, a highway with a zebra crossing and a traffic light - that is all that defines urban space in this film.
Méliès forms the principle of urban movement, or rather, the movement associated with the urban principle. It takes place around one house or in front of it, at a crossroads, in front of a porch and windows. At the same time, the movement is always multidirectional, with various people coming from different directions and freely leaving the frame. The freedom of movement in the frame, close to chaos, even without a single change in the place of action, is sure to create a city illusion.

\section{Change OF City locations}

Another successful principle of creating a city illusion is a frequent change of locations, including public urban areas.

Both of the techniques work well in "The Christmas Dream" ("Le Reve de Noel", 1900). Méliès changes locations a few times, showing first a private dwelling and then a square in front of a temple. Later, we can see bell-ringing boys inside the temple. There is a huge bell and pigeons on wooden beams around it, which immediately indicates the location of the bell somewhere very high, where birds feel good in the temple. Live birds give more naturalness to the bell, which is still too similar to a piece of scenery ... Then we go back to different rooms of the private house, or rather, a palace or a castle. The effect of free multidirectional movement is created in the scene in front of the temple. Pedestrians go in all directions at once, so it is impossible to track their movements, as our eyes seem to go out of focus. In addition, there appears a palanquin carried by someone's servants. It comes from the deep of the frame and goes around the camera towards the audience.

Natural changes in the distance between a camera, on the one hand, and actors and objects, on the other hand, with a camera still, create the impression of a more organic construction of screen dynamics. Too free and intense movement of a camera is often associated with the convention of cinema.

Even sooner than that, however, in the same film, there is a view of urban roofs that later becomes archetypical. The roofs stretch across the entire frame, demonstrating the density of urban development and creating a feeling of a cozy habitable space. The shapes of the gable tiled roof vary, and some windows can be seen. In general, the scene before us is a magnificent and charming "top floor" of the urban universe, "a city on the roofs", which will be repeatedly exploited both in Méliès's later films and in the cinema of subsequent years (primarily in the adventurous films of Louis Feuillade). In the distance, you can see a spire of a Gothic cathedral or a town hall. In the foreground on the left, there is a chimney going. On the right, two angels on the snow-covered tiles take boxes with gifts down the chimneys of the city dwellers. Nothing breaks 
the illusion of magic happening around. Both the angels and the city roofs look like the result of divine creation and harmony.

With all the peripherality of a city theme for Méliès, it rather significantly affects the atmosphere of some films. In "The Christmas Angel" ("L'Ange de Noel", 1905), for instance, Paris is shown as a shaky essence. From the point of view of traditional cinema, there are few locations here, but for Méliès there are quite a lot of them. After the interior of the poor house, we can see a spot in front of the church, where beggars and cripples gather. Immediately after the scene with the people who are leaving the church, being indifferent or irritated at a beggar girl, the action is transferred to the street full of shop windows.

This is the liveliest place in this film - the line of shop windows diagonally goes deep into the frame and looks like a quintessence of the urban aspect. Méliès gives a cutaway view of the shop, which creates the effect of openness and friendliness of urban public spaces. The street looks fun, anticipating a holiday. However, this is a deceptive effect, since it applies only to prosperous Parisians.

Yet here, as well as in front of the church, no one will give the poor girl a coin. Her attempts to beg will be met with hostility. Strangers here are shown as alien, callous, unwilling to take someone's sorrows to heart, even on Christmas Eve. While the church symbolizes the spiritual and duty, the butcher's shop in the foreground stands for the material, related to physical needs and pleasures. The girl appears to be alien anywhere she goes. The city represented by strangers, spiritual institutions and everyday life rejects her.

Next, the film visualizes the depletion of the human principle as compassion, mercy and kindness. It is depicted through the scenes of Paris being almost deserted. The next location is the bridges over the Seine. There are nearly no passers-by. The girl is barely walking. Seeing a couple of passers-by with an umbrella, she tries to talk to them, but in vain. There is no one else around. Only bridges, snow and the silhouette of the Palace of Justice (Palais de Justice) darkening in the background, which is a bitter irony from Méliès.

On the bridge, a poor rag-picker will help the girl. However, this assistance is not enough. After the bridge, we will see the character in a snow-covered landscape with no more signs of the city. Instead, we can see a desert hilly area with a well in the foreground. It seems that it is not the girl who has gone somewhere to the outskirts of Paris, but it is the city that has retreated further from the miserable character. There is no one to expect help from, nothing to hope for - there is simply no one around. It is completely empty.
The girl is found unconscious by some gentlemen in a car. In other words, instead of a pre-urban city, civilization comes to the rescue. Its main symbol at the beginning of the twentieth century - the car - literally enters the rural space, moves over the snow, ignores the cold and the blizzard. Sure enough, the director is far from consciously developing a confrontation yet - a pre-urban, static city with borders vs. a new technologically advanced, dynamic borderless civilization. However, this confrontation comes naturally.

In most films directed by Georges Méliès, there appears a patriarchal city with medieval houses, narrow streets and small squares. However, it is good, first of all, as an aesthetic phenomenon with no significant tasks or meanings assigned to the urban environment. As a decoration, such a city works well and is pleasing to the eye, maintaining a harmonious picture of the world where it is strong enough. Meanwhile, such a city does not save from anything where conflicts and catastrophes are brewing. In "The Christmas Dream" and "Joan of Arc" we have about the same collective image of a medieval city and a part of "non-academic medievalism" [9], or Romantic myth of the Middle Ages.

\section{CONCLUSION}

Thus, the first attempts to create a screen illusion of a city in the films of Méliès come together with the emergence of images of civilization and reflection on its future. It is easier to show the presence of civilization with the help of individual elements of the latest or fantastical technology of the future, rather than by building an integral space of a civilization or a city in the frame. Méliès follows the tradition of aestheticizing destructive activities of characters in a civilized / urban environment, which compensates for the prohibition of destruction in social reality and provides a virtual way out for destructive human energy.

Méliès's first views of the city are those of medieval towns. The images of urban streets, squares or roofs can both support the picture of life harmony, and, on the contrary, emphasize its artificial nature, depending on which plot develops in the scenery of the ideal urban environment.

One of the first simple methods of creating a city illusion is showing multidirectional movement of characters in front of a corner house or a house in the foreground with a street section behind it. Characters freely entering and leaving the frame enhance the effect of incorporation of one location into a certain urban environment, the "extension of the city" behind the scenes. Another technique is an intensive change of urban locations. The principles of picturing a city in the frame outlined by Georges Méliès, continue to evolve 
in modern cinema and television art (television, television series, television drama) as the most typical and technically convenient elements of screen art aesthetics.

\section{References}

[1] "The city of entertainment: notes, analyses, plots", ed. by E.V. Dukov, St. Petersburg, Dmitrij Bulanin, 2007, 284 p.

[2] S. Barber, "Projected Cities: Cinema and Urban Space", London, Reaktion Books, 2004, 208 p.

[3] "Cities of the world - the world of the city", Moscow, NII RAH Publ., 2009, 304 p.

[4] E.V. Salnikova. "Visual culture in the media space. Contemporary trends and historical excurses", Moscow, Progress-Tradiciya Publ., 2017, pp. 138-139.

[5] B. Mennel "Cities and Cinema", London, New York, Routledge, 2008, p. 9.

[6] K.E. Razlogov. "The image of a city in the cinema art. Between Metropolice and Matrix" in: "Cities of the world - the world of city", Moscow, NII RAH Publ., 2009, p. 90.

[7] N.M. Elcott "Artificial Darkness: An Obscure History of Modern Art and Media", Chicago, London, University of Chicago Press, 2016, pp. 135-149.

[8] "Complete Catalogue of Genuine and Original Star Films (Moving Pictures) manufactured by Geo. Melies of Paris", Paris, New York, Motion Pictures Catalogs, 1905, p. 84.

[9] V. Ortenberg, "In Search of the Holy Grail: The Quest for the Middle Ages", London, New York, Humbledon Continuum, 2006, pp. 175-176. 